\title{
Awareness of over the counter antibiotics to combat antimicrobial resistance
}

\author{
Sunita Sunil Patil*, Saket Agarwal
}

Department of pharmacology, D Y Patil Medical College and University, Kolhapur, Maharashtra, India

Received: 28 September 2019 Revised: 11 November 2019 Accepted: 12 November 2019

\section{*Correspondence to: \\ Dr. Sunita Sunil Patil, Email: drpsunita@ rediffmail.com}

Copyright: () the author(s), publisher and licensee Medip Academy. This is an openaccess article distributed under the terms of the Creative Commons Attribution NonCommercial License, which permits unrestricted noncommercial use, distribution, and reproduction in any medium, provided the original work is properly cited.

\begin{abstract}
Background: In India there is wide use of over the counter (OTC) antibiotics and unawareness of its harmful effects. In India dispensing antibiotics without prescription is a major contribution factor in development of antimicrobial resistance (AMR). The objectives of the present study were to evaluate awareness and proper use of OTC antibiotics in the community.

Methods: Responses to a questionnaire covering various aspects on awareness and usage of OTC antibiotics were obtained from 100 families and 100 pharmacy shops in the community by second year MBBS students after permission from institutional ethical committee. The study period was from January 2019 to June 2019.

Results: Among 100 responders 78\% used OTC antibiotics for frequently reported illness like common cold $(58 \%)$, body- ache $(19 \%)$, fever $(13 \%)$ and cough (10\%). Most common reason for using OTC antibiotic is to avoid high consultation fees (64\%).76\% pharmacy dispense antibiotics without prescription. $60 \%$ pharmacy unaware of increase chance of developing resistance due to OTC antibiotics. $80 \%$ pharmacy maintain register book and were aware of laws and regulations of OTC prescription but still $70 \%$ dispense drugs due to fear of losing sales and profit. 50\% pharmacy said they encourage patients to consult the physician and get the prescription. Most common antibiotic sold without prescription is amoxicillin (51\%) and azithromycin (38\%).

Conclusions: We have identified unawareness among people about use and harmful effects of using OTC antibiotics. Also pharmacies are not following rules and regulations for OTC drugs. So our aim is to increase public knowledge of proper use and harmful effects of OTC antibiotics and help our global program to reduce AMR.
\end{abstract}

Keywords: Awareness, OTC, Misuse, AMR

\section{INTRODUCTION}

According to the World Health Organization (WHO), "antibiotic resistance" is one of the biggest threats to global health. ${ }^{l}$ Antibiotic resistance happens when germs like bacteria and fungi develop ability to defeat the drugs designed to kill them. As a result these medicines become ineffective and resistant strains spread to others. Resistance to antimicrobials has been linked to over and underuse of antibiotics, with evidence of a cause-effect relationship. ${ }^{2,3}$ Other causes like unawareness and lack of knowledge of antibiotic resistance also contribute to above problem. In India, dispensing antibiotics without prescription [over the counter drugs- (OTC) drugs] is a major contributing factor in the irrational use of antibiotics leading to the development of anti-microbial resistance (AMR) a global crisis. ${ }^{4}$ The primary reason for people to start using medicines without professional help are advertisements on television, radio and print media, in addition getting advice from friends and family. Some other reasons for self-medication are the expensive healthcare system and think it is of too much hassle. Many developing countries have poor antibiotic dispensing laws. The provider and patient role and contribution are intertwined that give rise to a need to understand different motivating factors in different populations. ${ }^{5}$ 
To combat this global crisis it is mandatory to formulate proper and strict health care policies to reduce and regulate self-medication. Also general population should be educated about not using OTC antibiotics, prevent unnecessary use of antibiotics. People should be educated about harmful effects of antibiotic over use. ${ }^{6}$ Globally many strategies are made to reduce threat of AMR. The Norwegian national strategy against antibiotic resistance (2015-2020) to reduce antibiotic use by $30 \% .^{7}$ The European support national awareness-raising efforts through independent information and public education. Information campaigns are launched in many countries. India also has launched many strategies to reduce AMR but not properly implemented, also there is unawareness about proper use of antibiotics. WHO has warned that a post-antibiotic era will result in frequent infections and small injuries may result in death. ${ }^{8}$ So to increase awareness of antibiotic use and to see impact of OTC antibiotic use we have undertaken this study.

\section{METHODS}

\section{Study design}

Cross sectional survey conducted in D Y Patil medical college Kolhapur, Maharashtra after getting permission from Institutional ethical committee.

\section{Study population}

Community in selected area (100 families) in western Kolhapur and 100 pharmaceutical shops. Exclusion criteria, which are not willing to take part in the study.

\section{Plan of work}

The survey conducted with an aim to evaluate use of OTC drugs among people in community and 100 pharmaceutical shops to determine awareness and disadvantages of use and dispensing of OTC antibiotics. Study conducted by II year MBBS students. The study period was from January 2019 to June 2019. First students were made aware about AMR and its impact and measures to reduce resistance by taking lecture by faculty of pharmacology. One group of 20 students visited 100 families in selected area and other group of 20 students visited 100 pharmaceutical shops. Objectives, procedure of study were explained to the participants during the visit. Preformed questionnaire was handed to the head of each family member and person present in the pharmacy shop. Questionnaire for community and for pharmacy developed by the author and faculty of pharmacology department and underwent revisions as suggested by institutional research committee. Questionnaire includes questions for community, related to self-medication of antibiotics, their knowledge of antibiotic resistance and their attitude related to use of OTC antibiotics and for pharmacy, their attitude towards selling nonprescription antibiotic, knowledge of resistance, common antibiotics dispensed, and knowledge about legal aspect of dispensing antibiotics without prescription.

After collection of questionnaire, family members were made aware of not using OTC antibiotics. They were instructed about proper use of antibiotics and prevent self-medication and not sharing antibiotics. Pharmaceutical shop in-charge was requested not to dispense antibiotics without prescription and to keep record of dispensing antibiotics.

\section{Statistical analysis}

All data obtained was analyzed using the Microsoft Excel software. Descriptive analysis was performed on all the variables to obtain percentage.

\section{RESULTS}

In our study among 100 families, $70 \%$ were female who filled the form as head of the family. In 100 pharmaceutical shop $92 \%$ were male who filled the form. All shops were registered and shop owner had basic education (B Pharm/D Pharm) which is required to open the pharmacy shop.

\section{Survey of community}

In our study among 100 (families) responders $78 \%$ $(\mathrm{n}=78)$ take antibiotics without prescription for following reasons, mild illness, having previous experience and to avoid consultation fees.

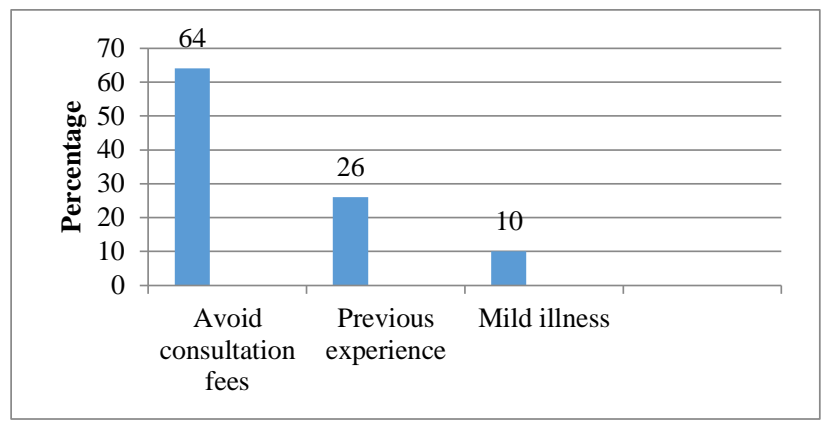

Figure 1: Factors for self-medication among participants.

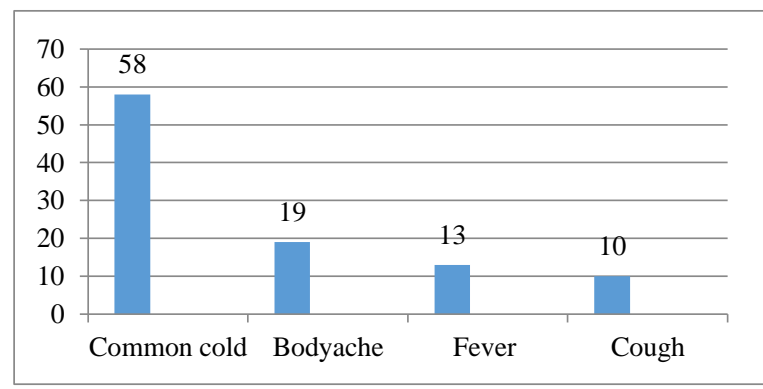

Figure 2: Various indications for use of OTC antibiotics. 
Table 1: Response to questionnaires (pharmacy).

\begin{tabular}{|c|c|c|c|}
\hline Item (questions) & Yes $(\%)$ & No $(\%)$ & Don't know (\%) \\
\hline 1. Do you dispense antibiotics without prescription & 76 & 24 & -- \\
\hline $\begin{array}{l}\text { 2. Do you think there is any problem if you dispense medication } \\
\text { without prescription }\end{array}$ & 30 & 60 & 10 \\
\hline $\begin{array}{l}\text { 3. Do antibiotics without prescription contributing to the } \\
\text { development of AMR }\end{array}$ & 20 & 20 & 60 \\
\hline $\begin{array}{l}\text { 4. Do you encourage patients to consult the physician and get a } \\
\text { prescription }\end{array}$ & 50 & 50 & -- \\
\hline 5. Refusing dispensing drug, will negatively affect sales and profits & 70 & 20 & 10 \\
\hline 6. Are there any laws for dispensing antibiotics without prescription & 80 & -- & 20 \\
\hline 7. Do you maintain register for antibiotic sale- & 80 & 20 & -- \\
\hline
\end{tabular}

From Figure 1, maximum 64\% took OTC antibiotics for avoiding consultation fees. $26 \%$ having previous experience and $10 \%$ as they had mild illness.

From Figure 2, 58\% participants bought antibiotic for common cold, $19 \%$ for bodyache, $13 \%$ for fever and $10 \%$ for cough.

\section{Survey for pharmacy shop}

From Table 1, 76\% dispense antibiotics without prescription. $60 \%$ pharmacies were unaware of increase chance of developing resistance due to OTC antibiotics. $80 \%$ maintain register and also were aware of laws and regulations of dispensing OTC drugs, but $70 \%$ still sold antibiotics thinking refusal of dispensing will negatively affect sales and profit. $50 \%$ pharmacy said they encourage patients to consult the physician and get the prescription.

From Figure 3, 76\% pharmacy dispense antibiotics without prescription and most commonly sold antibiotics were amoxicillin $51 \%$, azithromycin $38 \%$ and cefodex in $10 \%$.

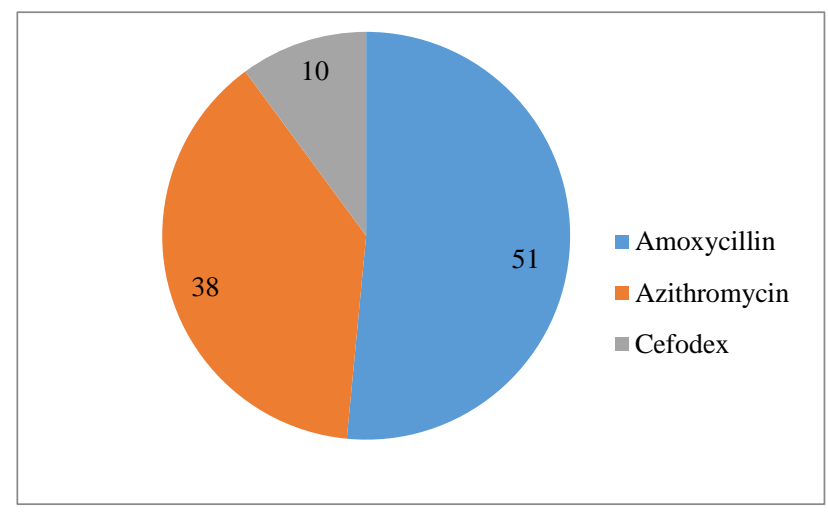

Figure 3: OTC antibiotics dispensed by pharmacy.

\section{Awareness among participants}

Awareness brought among community about harmful effects of use of OTC antibiotics, should not use OTC antibiotics, not sharing antibiotics. They were also instructed about proper use of antibiotics. Awareness among pharmacy shop for not dispensing antibiotics without prescription and to follow laws and regulations of dispensing OTC antibiotics.

\section{DISCUSSION}

In our study found $70 \%$ of female practiced purchase of OTC antibiotics. Published literature mention more female preponderance for OTC purchase. ${ }^{9}$ Our study shows $78 \%$ take OTC antibiotics. Such study done in Uganda $57 \%$ self-medicated with drugs with antibiotics. ${ }^{10}$ Reason for using OTC antibiotics, 64\% said it was because of high consultation fees of doctor. Use of OTC preparations in developing countries has been into practice for several reasons as; no regulations on selling and purchasing of medications, due to prior experience, negligence and poverty to some extent. ${ }^{11}$ The most common illness for purchase of OTC antibiotics in our study was common cold and body ache. Highest percentage for seeking antibiotics was for viral illnesses, results which are similar to the previous study conducted by Bertoldi et al. ${ }^{12}$ In our study participants were not aware of harmful effects of using unnecessary OTC antibiotics. Several other studies concluded that public responders have poor knowledge of antibiotics. ${ }^{13,14}$

In our study $76 \%$ of pharmacies $(n=76)$ dispensed antibiotics without prescription. A cross sectional study conducted in Saudi Arabia, reported 78 pharmacies dispensed antibiotic without prescription. ${ }^{15}$ Reason for this may be losing a client or patient, increased sale and profit pressure from owner or lack of awareness about rules and regulations against dispensing antibiotics without prescription. The present finding indicates that penicillin and macrolide group, are the most commonly dispensed antibiotics without prescription. Dispensing antibiotic without prescription considered to play a fundamental role in the development of AMR. Different studies suggest, countries with high level of AMR have a high incidence of non-prescription antimicrobial sales and use in community. India is the country, with high sale of non-prescription antibiotics. In preset study $80 \%$ were aware about laws and regulations for sale of non- 
prescription antibiotics but still sold antibiotics due to moreover lax medical regulations. There are few incidences where registration of pharmacy was withdrawn for sale of non-prescription antibiotics. The government should formulate proper healthcare policies and strictly follow rule and regulation to combat the problem and regulate responsible self-medication.

\section{CONCLUSION}

We have identified the unawareness among people about use and harmful effects of using OTC antibiotics. Also pharmacies do not follow rules and regulations for OTC drugs. So our aim is to bring and increase public knowledge of proper use, harmful effects due to improper use of antibiotics and avoid OTC antibiotic use and insist pharmacies to follow regulations laid for OTC antibiotics and avoid dispensing non-prescription antibiotics. We will conduct such survey every 6 monthly with the help of II year MBBS students where both students and community will be aware and help our global program to reduce AMR and prevent entering into post antibiotic era.

\section{ACKNOWLEDGEMENTS}

We acknowledge our II year MBBS students who participated in the study.

Funding: No funding sources

Conflict of interest: None declared

Ethical approval: The study was approved by the Institutional Ethics Committee

\section{REFERENCES}

1. Antibiotic resistance-Fact sheet. World Health Organization, 2016. Available at: http://www.who. $\mathrm{int} /$ mediacentre/factsheets/antibiotic-resistance/en/. Accessed on 19 September 2019.

2. Rezal RS, Hassali MA, Alrasheedy AA, Saleem F, Yusof FA, Godman B. Physicians' knowledge, perceptions and behaviour towards antibiotic prescribing: a systematic review of the literature. Expert Rev Anti Infect Ther. 2015;13:665-80.

3. Hawkey PM. Action against antibiotic resistance: no time to lose. Lancet. 1998;351:1298-9.

4. Goossens H, Ferech M, Stichele RV, Elseviers M. ESAC Project Group. Outpatient antibiotic use in Europe and association with resistance: a cross national database study. Lancet. 2005;365:579-87.
5. Barker A, Verhoeven K, Ahsan M, Alam S, Sharma $\mathrm{P}$, Sengupta S, et al. Social determinants of patient antibiotic misuse in Haryana, India. J Invest Med. 2016;64(4):935.

6. Bennadi D. Self-medication: a current challenge. J Basic Clin Pharm. 2014;5:19.

7. National Strategy against Antibiotic Resistance, 2015-2020. Norwegian Ministry of Health and Care Services; 2015.

8. Antibiotic resistance. Fact sheet-2017. Accessed on 16 June 2019. Available at: http://www.who.int/ mediacentre/factsheets/antibiotic-resistance/en/. Accessed on 19 September 2019.

9. Shroti R, Nayak N, Singh RM. A study on over the counter drugs in retail pharmacies in Indore city. Der Pharmacies Lettre. 2011;3(3):133-8.

10. Chioro A, Coll-Seck AM, Høie B, Moeloek N, Motsoaledi A, Rajatanavin R, et al. Antimicrobial resistance: a priority for global health action. Bull World Health Organ. 2015;93:439.

11. Parikh D, Sattigeri BM, Kumar A, Brahmbhatt S. A survey study on use of over the counter (OTC) drugs among medical students, nursing and clerical staff of a tertiary care teaching rural hospital Int J Res Med Sci. 2013;1(2):83-86.

12. Bertoldi AD, Camargo AC, Silveira MP, Menezes MP, Asscencao MC, Goncalves H. Self-medication among adolescents aged 18 years: the 1993 pelotas (Brazil) Birth cohort study. J Adolesc Health. 2014;55(2):175-81.

13. Togoobaatar G, Ikeda N, Ali M, Sonomjamts M, Dashdemberel S, Mori R, et al. Survey of nonprescribed use of antibiotics for children in an urban community in Mongolia. Bull World Health Organ. 2010;88:930-6.

14. Abasaeed AE, Vlcek J, Abuelkhair MA, Andrajati R, Elnour AA. A comparative study between prescribed and over-the-counter antibiotics. Saudi Med J. 2013;34:1048-54.

15. Al-Mohamadi A, Badr A, Mahfouz LB, Samargandi D, Ahdal AA. Dispensing medications without prescription at Saudi community pharmacy: extent and perception. Saudi Pharm J. 2011;21:13-8.

Cite this article as: Patil SS, Agarwal S. Awareness of over the counter antibiotics to combat antimicrobial resistance. Int J Basic Clin Pharmacol 2019;8:2697-700. 